\title{
POTENCIAL PRODUTIVO, RESISTÊNCIA À FERRUGEM DA FOLHA E QUALIDADE INDUSTRIAL DA FARINHA EM GENÓTIPOS DE TRIGO (1)
}

\author{
JOÃO CARLOS FELÍCIO $\left({ }^{2}\right)$; CARLOS EDUARDO DE OLIVEIRA CAMARGO $\left({ }^{(2,4)}\right.$; \\ MÁRCIA SOARES CHAVES $\left({ }^{(3)}\right.$; ANTONIO WILSON PENTEADO FERREIRA FILHO ${ }^{(2)}$
}

\begin{abstract}
RESUMO
Com o objetivo de avaliar o potencial de rendimento de grãos, a resistência à ferrugem da folha e as características tecnológicas da farinha, foram avaliados 18 genótipos de trigo provenientes de cruzamentos com a cultivar IAC 24, mais as cultivares controles IAC 24 e IAC 370, em experimentos instalados em condições de sequeiro nas localidades de Manduri (Zona A), Capão Bonito e Itapeva (Zona B) e Paranapanema (Zona C), no Estado de São Paulo, no período de 2003 a 2005. As avaliações dos genótipos ao agente causal da ferrugem da folha foram feitas no estádio de plântulas em casa de vegetação, onde os genótipos foram submetidos à inoculação individualmente com esporos de 12 raças de Puccinia triticina, as quais representavam o espectro de virulência do patógeno ocorrente no Brasil e também sob infecção natural no campo. Em oito genótipos descendentes da cultivar IAC 24 observaramse níveis adequados de resistência não-específica à ferrugem da folha, com reações suscetíveis porém com baixa severidade, consistentemente ao longo dos anos/locais. O melhor rendimento de grãos foi obtido pelo genótipo 7 (PF87373/IAC 24), entretanto não diferindo dos genótipos 12, 18, 4 e 6. De acordo com os paramentos alveográficos e farinográficos, os genótipos 4, 5, 8, 9, 11, 15 e 18 se destacaram pela qualidade industrial e suas farinhas foram de classe superior. Os genótipos que se destacaram em relação às três características estudadas são potencialmente úteis aos programas de melhoramento genético como doadores de alelos favoráveis.
\end{abstract}

Palavras-chave: Triticum aestivum L., rendimento de grãos, Puccinia triticana, melhoramento.

\section{ABSTRACT \\ GRAIN YIELD POTENTIAL, LEAF RUST RESISTANCE AND FLOUR TECHNOLOGICAL CHARACTERISTICS IN WHEAT GENOTYPES}

This work aimed to evaluate eighteen wheat genotypes obtained from crosses with the cultivar IAC 24 for potential grain yield, leaf rust resistance and flour technological characteristics in experiments carried out in upland conditions at Manduri (Zone A), Capão Bonito and Itapeva (Zone B) and Paranapanema (Zone C), in the State of São Paulo, Brazil, during 2003-2005. Evaluations of the genotypes for the leaf rust causal agent were made at the seedling stage in greenhouse, where the genotypes were individually inoculated with spores of 12 races of Puccinia triticina, represented by the pathogen virulence range occurring in Brazil, and also under natural infection in the field. Eight lines descending from IAC 24 showed adequate levels of non-specific resistance, with susceptible reactions but of low severity, consistently over the years / locations. The highest grain yield was shown by the genotype 7 (PF87373/IAC 24), not differing from genotypes 12, 18, 4 and 6. According to alveographic and farinograph parameters, the genotypes $4,5,8,9,11,15$ and 18 stood out for their industrial quality and superior flour. The selected genotypes featuring the best agronomical traits are potentially useful for breeding programs as donors of favorable alleles.

Key words: Triticum aestivum L., grain yield, Puccinia triticana, breeding.

(1) Recebido para publicação em 1. ${ }^{\circ}$ de julho de 2009 e aceito em 9 de março de 2010.

(2) Centro de Análise e Pesquisa Tecnológica dos Agronegócios de Grãos e Fibras, Instituto Agronômico (IAC) Caixa Postal 28, 13012-970 Campinas (SP). E-mail: jfelicio@iac.sp.gov.br $\left(^{*}\right)$ Autor correspondente, ferreira@iac.sp.gov.br

(3) Embrapa Trigo, Caixa Postal 451, 99010-100 Passo Fundo (RS). E-mail: mchaves@cnpt.embrapa.br

(4) In memoriam. 


\section{INTRODUÇÃO}

No passado, a cultura do trigo ocupou uma posição de destaque na agricultura brasileira. No entanto, problemas fitossanitários, de políticas públicas e de coordenação da cadeia produtiva, desestimularam os produtores rurais, acarretando a diminuição gradual do cultivo do trigo e a grande dependência externa na década de 90 . Nos últimos anos, cerca de $70 \%$ do trigo consumido no Brasil foi proveniente de outros países, em especial da Argentina (Rossi e Neves, 2004). Atualmente, no Brasil são consumidos, internamente, cerca de 10,25 milhões de toneladas de trigo, tendo em 2007 produzido apenas 3,8 milhões de toneladas. Esse valor faz com que o trigo seja o segundo item de maior participação na pauta de importações brasileiras entre as commodities, sendo menor apenas que a importação de petróleo. As divisas despendidas nas importações de trigo são de tal montante que, se aplicadas internamente, possibilitariam custear uma produção próxima do consumo total. Em 2007, as importações de trigo totalizaram um gasto próximo de US\$ 1,57 bilhão, dinheiro que permitiria o custeio de cerca de 3,5 milhões de hectares, com potencial para produzir acima de 7,0 milhões de toneladas (HUBNER, 2008).

Aumentar a produção interna de cereais e mantêla em níveis sustentáveis são os principais desafios para o futuro, e atingir essa meta de maneira que não comprometa a integridade do ambiente e a saúde pública é um desafio maior ainda. Isto é ainda mais sério considerando que nas últimas décadas o aumento na produção de cereais foi acompanhado pelo aumento na produção e comercialização de pesticidas (TILMAN et al., 2002).

A avaliação de cultivares de trigo em diferentes zonas tritícolas do Estado de São Paulo permitiu concluir que os genótipos de trigo possuem comportamento regional diferenciado, ea interação anos $x$ locais foi altamente significativa nas condições de sequeiro (Felicio et al., 2000). Os genótipos IAC 289, IAC 340 e BR 18 tiveram bom rendimento de grãos, enquanto os genótipos IAC 24, IAC 120, IAC 227, OCEPAR 14, IAC 348, Panda, BR 18, IAC 319, IAPAR 60, IAC 332 e IAC 347 foram tolerantes à toxicidade de alumínio. A farinha procedente dos genótipos semeados em Itaberá (Zona B) foi de melhor qualidade tecnológica em relação à proveniente dos semeados em Maracaí (Zona A) (Felicio et al., 2000).

Dentre os problemas fitossanitários que afetam a cultura do trigo, a ferrugem da folha, causada por Puccinia triticina Erikes (ANIKSTER et al., 1997), é a mais severa e prevalecente doença, tanto no Brasil quanto em toda a região do Cone Sul da América do Sul. A doença ocorre anualmente, causando vastas epidemias em cultivares suscetíveis ou moderadamente suscetíveis, e pode ocorrer redução superior a 50\% no rendimento de grãos. Estima-se que na América do Sul, epidemias de ferrugem da folha causaram perdas de US\$170 milhões durante o período de 1996 a 2003. Considerando as grandes áreas semeadas com cultivares que requerem controle químico nesta região, estima-se que o custo anual total de aplicações de fungicidas para o controle da ferrugem da folha, em um ano de epidemia moderada, seja de US\$ 50 milhões (GERMÁN et al., 2007; SINGH et al., 2009).

A população de $P$. triticina neste ambiente é extremamente dinâmica, sendo frequente o surgimento de novas raças, que podem se tornar importantes devido à sua ampla disseminação e/ou pela superação da resistência de uma cultivar amplamente cultivada. $\mathrm{O}$ número reduzido de genes de resistência ainda efetivos torna cada vez mais difícil o controle da doença através da resistência genética. Por esse motivo, a pesquisa e a utilização de formas de resistência mais estáveis, como a resistência parcial de planta adulta (RPA) é uma necessidade cada vez mais urgente. Este tipo de resistência é a alternativa mais promissora para integrar estratégias de controle, uma vez que não causa a intensa pressão de seleção para raças virulentas do patógeno, como ocorre com a resistência específica a raças, com base em genes isolados (CHAves et al., 2005; CHAVES e BARCELLOS, 2006; ChAVES et al., 2009).

De acordo com Felicio et al. (2004), a cultivar IAC 24 possui resistência de planta adulta (RPA), e o desenvolvimento da doença é mais intenso nos estádios iniciais da cultura com decréscimo da intensidade de infecção na fase adulta, associada a uma necrose na ponta da folha bandeira - LTN (do inglês Leaf Tip Necrosis). A LTN indica a presença do gene Lr34 e quando combinado a outros genes aditivos de menor efeito condiciona resistência durável à ferrugem da folha do trigo (SINGH, 1992).

O conceito de qualidade, em relação aos grãos de trigo, está intimamente relacionado com o destino industrial da farinha a ser produzida. Assim, o trigo hexaplóide (T.aestivum), o farinheiro, é classificado pela dureza de seu grão (textura do endosperma) em duro, semiduro e suave (brando). Os trigos duros e semiduros são utilizados principalmente na panificação, ou em mistura com os brandos, que por sua vez são utilizados na elaboração de bolachas e produtos de confeitaria (PeÑa et al., 1998).

Oobjetivo deste trabalho foi avaliar o desempenho dos novos genótipos de trigo (T. aestivum.) quanto ao rendimento de grãos, resistência à ferrugem da folha, qualidade industrial da farinha quando comparados às cultivares IAC 24 e IAC 370, cultivares com boa adaptação e boas qualidades industriais da farinha. 


\section{MATERIAL E MÉTODOS}

Foramsemeadosexperimentosem diferentes regiões tritícolas do Estado de São Paulo no período de 2003 a 2005, em ambiente de sequeiro nas localidades de Manduri (Zona A), Capão Bonito e Itapeva (Zona B) e em Paranapanema (Zona C). Para a instalação dos experimentos adotaramse as recomendações da Comissão Técnica de Trigo da Secretaria Agricultura e do Abastecimento do Estado de São Paulo (InSTituto Agronômico, 2002). As informações quanto à genealogia, o ciclo em dias, da emergência ao início do espigamento (estádio de crescimento 10.1 na escala de LARGE, 1954), da emergência à maturação plena (estádio de crescimento 11.4 na escala de LARGE, 1954), e a altura das plantas estão na tabela 1 .

Os experimentos foram delineados em blocos ao acaso, compostos de vinte genótipos com quatro repetições por local. Cada parcela foi constituída de oito linhas de 3 metros de comprimento, com espaçamento de $0,15 \mathrm{~m}$ entre si, com separação lateral de $0,60 \mathrm{~m}$ entre as parcelas. Procedeu-se à semeadura com 80 sementes viáveis por metro de sulco, sendo efetuada a colheita da área total das parcelas.

A adubação mineral foi feita a lanço antes da semeadura e, posteriormente, incorporada ao solo. As quantidades de fertilizantes aplicadas nos diferentes locais foram definidas de acordo com as recomendações de adubação e calagem para o Estado de São Paulo ( RAIJ et al., 1996).
O controle de pragas foi realizado com a aplicação de inseticidas, de acordo com as recomendações da Comissão Técnica de Trigo da Secretaria Agricultura e do Abastecimento do Estado de São Paulo (Instituto Agronômico, 2002).

As avaliações para resistência à ferrugem da folha foram realizadas em dois estádios:

No estádio de planta adulta, a ferrugem-dafolha (Puccinia triticina Rob.ex-Desm. f.sp. tritici Erichs) foi avaliada, sob condições de infecção natural após o florescimento das plantas (estádio de crescimento 11.2 na escala de LARGE, 1954), por meio da escala modificada de Cobb, conforme Schramm et al. (1974). Essa escala vai de 0 a $99 \%$ de área foliar infectada, complementada pelo tipo de reação: $\mathbf{S}=$ suscetível (uredossoro grande, coalescente, sem necrose e sem clorose); MS = moderadamente suscetível (uredossoro médio, que pode ou não estar associado com clorose); $\mathbf{M R}=$ moderadamente resistente (uredossoro pequeno a médio, frequentemente circundado por clorose ou necrose); $\mathbf{R}=$ resistente (uredossoro minúsculo, rodeado de áreas necróticas ou cloróticas).

Em casa de vegetação, foram submetidas à inoculação individualmente 12 raças de Puccinia triticina, no estádio de plântulas, as quais representavam o espectro de virulência do patógeno ocorrente no Brasil (CHAVEs et al., 2005), em condições controladas da Embrapa Trigo, Passo Fundo (RS). As raças foram

Tabela 1. Genealogia dos genótipos, características agronômicas do ciclo em dias da emergência ao inicio do espigamento e da emergência a maturação plena e a altura média dos genótipos de trigo avaliados, em condições de sequeiro em Capão Bonito, no Estado de São Paulo, de 2003 a 2005

\begin{tabular}{|c|c|c|c|}
\hline Genealogia & Espigamento & Maturação & Altura \\
\hline & \multicolumn{2}{|c|}{- dias -} & $\mathrm{cm}$ \\
\hline 1- GD 9017/IAC 24 & 65 & 125 & 100 \\
\hline 2- IAC 24 & 65 & 125 & 90 \\
\hline 3- GD 9017/IAC 24 & 65 & 121 & 85 \\
\hline 4- BUCK"S"/BJY"S"//GJO”S"/EMU"S"/3/IAC 24 & 65 & 125 & 85 \\
\hline 5- CHAT”S"/CEP7780//PRL/BOW"S"/3/IAC 24 & 65 & 121 & 75 \\
\hline 6- TRIGO BR 35/IAC 24 & 65 & 121 & 75 \\
\hline 7- PF 87373/IAC 24 & 60 & 121 & 85 \\
\hline 8- BOW”S"/BUC"S"//IAC 24 & 65 & 121 & 80 \\
\hline 9- RL6010/5*INIA66//IAC 24/IAC 287 & 65 & 125 & 85 \\
\hline 10- IAC 370 & 75 & 130 & 90 \\
\hline 11- IAC 24 (IRR)/IAC 120 & 65 & 125 & 80 \\
\hline 12- IAS54/ALD”S”//IAC 24/IAC 287 & 65 & 125 & 90 \\
\hline 13- KAUZ/IAC 24 & 65 & 125 & 85 \\
\hline 14- BOW//BUC/BUL/3/IAC 24 & 60 & 121 & 90 \\
\hline 15- VEE//DOVE/BUC/3/IAC 24 & 65 & 125 & 80 \\
\hline 16- RL6010/5*INIA66//IAC 24/IAC 120 & 65 & 125 & 85 \\
\hline 17- IAS 54/ALD"S"//IAC 24/IAC 287 & 65 & 121 & 100 \\
\hline 18- KAUZ/3/TOB/CTFN/4/BB/BLO"S"/5/TAN"S"/6/IAC 24/7/IAC 120 & 65 & 125 & 90 \\
\hline 19- $\mathrm{F}_{3}$ 71/TRM//CNO79/3/IAC 24/4/IAC 24 & 65 & 125 & 85 \\
\hline 20- IAC 24/YAVAROS & 65 & 125 & 80 \\
\hline
\end{tabular}


provenientes do banco de raças do patógeno, mantido por essa instituição. Cada raça corresponde a uma combinação de avirulência/virulência, com possíveis variações em função de genes sensíveis à temperatura, e cada combinação de virulência é representada por um código, de acordo com o Sistema Norte-Americano de Nomenclatura (LONG e Kolmer, 1989). No Brasil, estas combinações de virulência são também designadas pela letra $\mathrm{B}$, seguida pelo número de ordem de identificação de cada raça no país.

A inoculação foi realizada com os uredosporos do fungo resultantes da multiplicação de inóculo. Foi feita uma suspensão dos esporos em óleo mineral, com concentração de $10^{5}$ a $10^{6}$ esporos $\mathrm{mL}^{-1}$, a qual foi aspergida sobre as plântulas dos genótipos a serem avaliados, 7-9 dias após sua emergência, quando a primeira folha estava completamente expandida. Após a inoculação, as plântulas foram incubadas em câmara úmida, no escuro, por 12 horas. A seguir, as plântulas foram transferidas para casa de vegetação totalmente isolada do ambiente externo, com condições controladas de temperatura $\left(22 \pm 2{ }^{\circ} \mathrm{C}\right)$ e umidade $(80 \%)$ até o aparecimento dos sintomas.

O aparecimento dos sintomas ocorreu 10 a 12 dias após a inoculação, e a seguir procedeu-se à avaliação da reação dos genótipos, observando-se o tipo de infecção correspondente ao sintoma, de acordo com RoELFs et al. (1992). Foram considerados resistentes os genótipos com reação 0 - ; - 1 e 2 (e suas variações para mais ou menos) e suscetíveis aqueles com tipo de infecção 3 e 4 (e suas variações para mais ou menos).

O ciclo das cultivares foi determinado pelo número de dias decorridos da emergência das plântulas até a maturação. As cultivares com ciclo da emergência à maturação de 110 a 120, 121 a 130 e acima de 130 dias foram consideradas de ciclo precoce, médio e tardio respectivamente.

A altura das plantas foi medida em centímetros no campo, na época da maturação, do nível do solo ao ápice da espiga, com exclusão das aristas, estimando-se a média de diferentes pontos de cada parcela.

A avaliação de rendimentos de grãos foi realizada pesando-se, em gramas, a produção total de cada parcela, a qual foi extrapolada para quilogramas por hectare.

Os experimentos foram analisados conjuntamente, avaliando-se efeitos de anos, locais, genótipos e das interações anos $\mathrm{x}$ locais, anos $\mathrm{x}$ genótipos, locais $\mathrm{x}$ genótipos e anos $\mathrm{x}$ locais $\mathrm{x}$ genótipos. Utilizou-se para a comparação das médias o teste de Duncan, de acordo com Pimentel-Gomes (1990).
Os genótipos de trigo foram avaliados em relação às seguintes características tecnológicas:

Peso $^{(5)}$ do hectolitro: utilizando a balança Dalle Molle, e expresso em $\mathrm{kg} \mathrm{hL}^{-1}$, conforme procedimento descrito na Instrução Normativa $\mathrm{N}^{\circ} 7$, do Ministério da Agricultura e do Abastecimento (Brasil, 2001).

Rendimento de extração de farinha (moagem): empregando-se o moinho experimental "Brabender Quadrumat Senior", trabalhando com $2 \mathrm{~kg}$ de grãos, com base no método da AACC n. ${ }^{\circ} 26-10$ A (AACC, 1995). Os grãos tiveram seu teor de água ajustado para $15 \%$, 16-24 horas antes da moagem. A extração de farinha representa a porcentagem de farinha obtida em relação ao total de material obtido da moagem.

Número de queda (Falling Number): determinado pelo método n. ${ }^{\circ}$ 56-81B da American Association of Cereal Chemists (AACC, 1995), em grãos triturados em moinho Perten 3100 (Perten Instruments, Huddinge, Suécia), com peneira de 0,8 mm.

Propriedades de mistura da massa: determinadas no farinógrafo "Brabender", pelo sistema farinha-água, de acordo com o método n..$^{\circ}$ 54-21 da AACC (AACC, 1995). Misturam-se $50 \mathrm{~g}$ de farinha (na base de $14 \%$ de umidade) com água em quantidade suficiente para centralizar a curva na linha de 500 unidades farinográficas (U.F.). Essa quantidade de água expressa como \% em relação à farinha, é referida como "Absorção". O tempo de desenvolvimento da massa (TDM) é o tempo (min) necessário para alcançar a consistência máxima; estabilidade (EST) é o tempo (min) em que a curva permanece na linha de 500 U.F. e índice de tolerância à mistura (ITM) é a diferença (em U.F.) medida no topo da curva, no pico, até o topo da curva 5 minutos após o pico.

Propriedades de extensão da massa: determinadas no equipamento Alveógrafo "Chopin", de acordo com o método da AACC n. ${ }^{\circ}$ 54-30A (AACC, 1995). Os parâmetros básicos das curvas alveográficas estudados foram: pressão máxima $(\mathrm{P})$; abscissa média de ruptura (L); índice de configuração da curva (P/L) e a energia de deformação da massa (W) ou trabalho mecânico necessário para expandir a bolha até sua ruptura, expressa em $10^{-4}$ Joules.

Teor de glúten: determinado em aparelho Glutamatic, pelos métodos 38-10 e 38-12A, da AACC (1995), expresso em porcentagem (\%).

\section{RESULTADOS E DISCUSSÃO}

Os dados médios do ciclo da emergência ao inicio do espigamento e da emergência à maturação plena, e a

(5) Leia-se massa, de acordo com o Sistema Internacional de Unidades. 
altura média (Tabela 1), caracterizaram a cultivar IAC 370 como de ciclo tardio, sendo os demais genótipos avaliados como de ciclo médio. Os genótipos 1 (GD 9017/IAC 24) e 17 (IAS 54 / ALD"S" / / IAC 24/IAC 287) foram os mais altos $(100 \mathrm{~cm})$ seguidos dos genótipos 2, 10, 12, 14 e 18 que também foram considerados de porte alto $(90 \mathrm{~cm})$. Os demais genótipos são de porte baixo (semianão).

As análises estatísticas individuais dos experimentos dentro de anos mostraram efeitos altamente significativos para genótipos, locais e para a interação genótipos $x$ locais, demonstrando o comportamento diferencial dos genótipos dentro de cada localidade avaliada. A análise conjunta entre anos apresentou efeito altamente significativo entre os mesmos e genótipos de acordo com a tabela 2 . Observou-se que o melhor rendimento médio foi de $2962 \mathrm{~kg} \mathrm{ha}^{-1}$ em 2003 e o menor rendimento médio foi de $2304 \mathrm{~kg} \mathrm{ha}^{-1} \mathrm{em} \mathrm{2005,} \mathrm{portanto,} \mathrm{também} \mathrm{os} \mathrm{efeitos} \mathrm{do}$ fator ano influenciaram sobre o potencial produtivo dos genótipos, provavelmente devido às grandes variações pluviométricas em cada ano.

O rendimento de grãos do genótipo 7 (PF 87373/ IAC 24) foi o melhor no triênio $3098 \mathrm{~kg} \mathrm{ha}^{-1}$, mas não diferindo do rendimento dos genótipos 12, 18, 4 e 6 . O menor rendimento foi obtido pelo genótipo 13 (KAUZ/ IAC 24).

No período abrangido pela realização dos experimentos, houve grande variação na ocorrência das raças, não só na sua frequência como também no aparecimento de novas raças em infecções natural no campo (Chaves et al., 2005; GeRMÁn et al., 2007). Considerando-se a reação dos genótipos avaliados no estádio de plântula, verificou-se que as cultivares IAC 370 e IAC 24 foram suscetíveis a todas as raças de $P$. triticina testadas, bem como os genótipos descendentes de IAC 24 representados pelos números 1, 4, 6, 12, 14, 17, 19 e 20 (Tabela 3). Os demais genótipos, também

Tabela 2. Produtividade média de grãos e análise da variância conjunta dos genótipos de trigo avaliados em condição de sequeiro, nas localidades de Manduri Zona A, Capão Bonito e Itapeva Zona B e Paranapanema Zona C, no período de 2003 a 2005, no Estado de São Paulo

\begin{tabular}{|c|c|c|c|c|c|}
\hline Genótipos & 2003 & 2004 & 2005 & Média & $\%$ \\
\hline & & & $-\mathrm{kg} \mathrm{ha}^{-1}$ & & \\
\hline 1- GD 9017/IAC 24 & $3288 \mathrm{~b}-\mathrm{c}$ & $2787 \mathrm{c}-\mathrm{d}$ & $2251 \mathrm{c}-\mathrm{e}$ & $2775 \mathrm{a}-\mathrm{c}$ & 103,78 \\
\hline 2- IAC 24 & $3165 \mathrm{~b}-\mathrm{e}$ & $2626 \mathrm{~d}-\mathrm{f}$ & 2317 b-e & $2702 \mathrm{~b}-\mathrm{d}$ & 100,00 \\
\hline 3- GD 9017/ IAC24 & $2731 \mathrm{f}-\mathrm{g}$ & $2399 \mathrm{f}$ & 2065 e & 2398 d-e & 89,68 \\
\hline 4 - BUCK"S"/BJY"S"//GJO"S"/EMU”S"/3/IAC 24 & $3361 \mathrm{a}-\mathrm{b}$ & $2857 \mathrm{~b}-\mathrm{d}$ & 2324 b-e & $2847 \mathrm{a}-\mathrm{c}$ & 106,47 \\
\hline 5- CHAT”S"/CEP7780//PRL/BOW"S"/3/IAC 24 & 2884 d-f & $2643 \mathrm{~d}-\mathrm{f}$ & 2199 ce & $2575 \mathrm{c}-\mathrm{e}$ & 96,30 \\
\hline 6- TRIGO BR 35/IAC 24 & 3154 b-e & $3001 \mathrm{a}-\mathrm{c}$ & $2286 \mathrm{c}-\mathrm{e}$ & $2813 \mathrm{a}-\mathrm{c}$ & 105,20 \\
\hline 7- PF 87373/IAC 24 & 3645 a & $3089 a-b$ & $2560 a-b$ & 3098 a & 115,86 \\
\hline 8- BOW"S"/BUC"S"//IAC 24 & 2894 d-f & 2970 a-c & $2271 \mathrm{c}-\mathrm{e}$ & $2711 \mathrm{~b}-\mathrm{d}$ & 101,38 \\
\hline 9- RL6010/5*INIA66//IAC 24/IAC 287 & $2852 \mathrm{~d}-\mathrm{g}$ & 2819 b-d & $2126 \mathrm{e}$ & $2599 \mathrm{c}-\mathrm{e}$ & 97,20 \\
\hline 10 - IAC 370 & $2995 \mathrm{c}-\mathrm{f}$ & 2465 e-f & $2480 \mathrm{a}-\mathrm{c}$ & 2646 b-e & 100,00 \\
\hline 11- IAC 24 (IRR)/IAC 120 & $2797 \mathrm{f}-\mathrm{g}$ & $2642 \mathrm{~d}-\mathrm{f}$ & $2278 \mathrm{c}-\mathrm{e}$ & $2572 \mathrm{c}-\mathrm{e}$ & 96,19 \\
\hline 12- IAS54/ALD”S"//IAC 24/IAC 287 & $3174 \mathrm{~b}-\mathrm{d}$ & 3198 a & $2625 \mathrm{a}$ & $2999 a-b$ & 112,15 \\
\hline 13- KAUZ/IAC 24 & $2053 \mathrm{~h}$ & 2627 d-f & $2276 \mathrm{c}-\mathrm{e}$ & $2318 \mathrm{e}$ & 86,69 \\
\hline 14- BOW//BUC/BUL/3/IAC 24 & $2952 \mathrm{c}-\mathrm{f}$ & 2980 a-c & $2190 \mathrm{de}$ & $2707 \mathrm{~b}-\mathrm{d}$ & 101,23 \\
\hline 15- VEE//DOVE/BUC/3/IAC 24 & $2794 \mathrm{f}-\mathrm{g}$ & $2583 \mathrm{~d}-\mathrm{f}$ & 2156 e & $2511 \mathrm{c}-\mathrm{e}$ & 93,90 \\
\hline 16- RL6010/5*INIA66//IAC 24/IAC 120 & $3072 b-f$ & 2679 d-f & 2306 b-e & 2685 b-d & 100,41 \\
\hline 17- IAS 54/ALD”S"//IAC 24/IAC 287 & $2544 \mathrm{~g}$ & $2746 \mathrm{c}-\mathrm{e}$ & 2194 d-e & 2494 c-e & 93,27 \\
\hline 18- KAUZ/3/TOB/CTFN/4/BB/BLO"S"/5/TAN"S"/6/IAC 24/7/IAC 120 & $3286 \mathrm{~b}-\mathrm{c}$ & $3000 \mathrm{a}-\mathrm{c}$ & 2623 a & $2969 a-b$ & 111,04 \\
\hline 19- $\mathrm{F}_{3}$ 71/TRM//CNO79/3/IAC 24/4/IAC 24 & $2773 \mathrm{f}-\mathrm{g}$ & $2853 \mathrm{~b}-\mathrm{d}$ & 2440 a-d & $2688 \mathrm{~b}-\mathrm{d}$ & 100,52 \\
\hline 20- IAC 24/YAVAROS & $2831 \mathrm{e}-\mathrm{g}$ & $2635 \mathrm{~d}-\mathrm{f}$ & 2110 e & $2526 \mathrm{c}-\mathrm{e}$ & 94,47 \\
\hline Média & 2962 A & $2780 \mathrm{~B}$ & $2304 \mathrm{C}$ & 2682 & - \\
\hline Anos & - & - & - & $67,95 * *$ & - \\
\hline Genótipo & $10,54 * *$ & $5,59 * *$ & $3,76^{*}$ & $3,45^{*}$ & - \\
\hline Local & $492,97 * *$ & $64,73 * *$ & $403,98 * *$ & - & - \\
\hline Genótipo x local & $3,01 * *$ & $5,22 * *$ & $2,13^{*}$ & - & - \\
\hline $\mathrm{CV}(\%)$ & 14,01 & 12,91 & 14,65 & 6,87 & - \\
\hline
\end{tabular}

Médias para comparação da produtividade de grãos entre cultivares por ano e na média geral em letras minúsculas e médias para comparação entre anos em letras maiúsculas. Médias seguidas por letras distintas diferem entre si pelo teste de Duncan a 5\%. *;** significativo a $5 \%$ e $1 \%$ respectivamente.

\% em relação as média das testemunhas IAC 24 e IAC $370\left(2.674\right.$ kg.ha $\left.{ }^{-1}\right)$. 
Tabela 3. Tipo de infecção de genótipos de trigo a 12 raças de Puccinia triticina as quais representam o espectro de virulência do patógeno no Brasil em condições controlada em casa de vegetação

\begin{tabular}{|c|c|c|c|c|c|c|c|c|c|c|c|c|}
\hline Gen. & B 35 & В 37 & B 38 & В 39 & B 40 & B 41 & B 43 & B 45 & В 48 & В 49 & B 50 & B 51 \\
\hline 1 & 3 & 3 & 3 & 3 & 3 & 3 & 3 & 3 & 3 & 3 & 3 & 3 \\
\hline 2 & 3 & 3 & 3 & 3 & 3 & 3 & 3 & 3 & 3 & 3 & 3 & 3 \\
\hline 3 & 32 & ; & $11+$ & 0 & 3 & 2 & 0 & 3 & 3 & ;1 & 3 & $23-$ \\
\hline 4 & 3 & 3 & 3 & 3 & 3 & 3 & 3 & 3 & 3 & 3 & 3 & 3 \\
\hline 5 & 3 & 3 & 3 & $3-$ & 3 & $03(1 \mathrm{P})$ & 3 & $; 2(1 \mathrm{pu})$ & 3 & 3 & 3 & 3 \\
\hline 6 & 3 & 3 & 3 & 3 & 3 & 3 & 3 & 3 & 3 & 3 & 3 & 3 \\
\hline 7 & 3 & ; & ;1+ & 3 & 3 & 0 & 32 & 3 & 32 & 3 & ;1 2(pu) & 3 \\
\hline 8 & 3 & $0 ; 2$ & $; 1$ & 3 & 3 & 0 & $3-$ & 3 & $3-$ & 3 & 21 & 3 \\
\hline 9 & 0 & 0 & 3 & 0 & ; & 0 & 3 & 0 & 3 & 0 & 3 & ; \\
\hline 10 & 3 & 32 & 3 & 3 & $3-2(2 \mathrm{P})$ & $32+(\mathrm{pu})$ & 3 & 3 & 3 & 3 & 3 & 3 \\
\hline 11 & 3 & 3 & $213(\mathrm{pu})$ & 3 & 3- & ; & 3 & $31 ;(\mathrm{pu})$ & $3-$ & 3 & 3 & 3 \\
\hline 12 & 3 & $32(\mathrm{pu})$ & 3 & 3 & $3-$ & 3 & 3 & 3 & 3 & 3 & 3 & 3 \\
\hline 13 & 3- & ; & 2 & 0 & $3-$ & 12 & 0 & 3 & 3 & $3=1$ & 3 & 3 \\
\hline 14 & 3 & 3 & 3 & $3-$ & 3 & 3 & 3 & 3 & 3 & 3 & 3 & 3 \\
\hline 15 & 2 & $1+2$ & 23 & $32(\mathrm{pu})$ & 2 & $22+$ & 32 & 3 & $22+3(\mathrm{pu})$ & ;1 & $22+$ & 2 \\
\hline 16 & 3 & 3 & $123(\mathrm{pu})$ & 3 & $3-$ & ; & 3 & 32 & 32 & 3 & 3 & 3 \\
\hline 17 & 3 & 3 & 3 & 3 & $3-$ & 3 & 3 & 3 & 3 & 3 & 3 & 3 \\
\hline 18 & 3 & 3 & 3 & 01 & 3 & 3 & 3 & ; & 3 & 3 & 3 & 3 \\
\hline 19 & 3 & 3 & 3 & 3 & 3 & 3 & 3 & 3 & 3 & 3 & 3 & 3 \\
\hline 20 & 3 & 3 & 3 & 3 & $3-$ & 3 & 3 & 3 & 3 & 3 & 3 & 3 \\
\hline
\end{tabular}

Resistência: $0, ;, 1,1+, 2,2+\quad(p u)=$ pústulas.

Suscetibilidade:3,3-,3= $\quad(\mathrm{P})=$ planta.

descendentes de IAC 24, foram suscetíveis a no mínimo quatro e no máximo a 10 raças do patógeno dentre as 12 testadas. Não foi observado genótipo suscetível, ao nível de reação tipo 4 , sendo todas as reações de suscetibilidade do tipo 3 e suas variações.

Entretanto, as avaliações no estádio de planta adulta revelaram que o comportamento da maioria dos genótipos descendentes de IAC 24 foi semelhante ao pai, parcialmente resistente ao longo dos anos/locais testados (Tabela 4). Esses genótipos são, potencialmente, portadores de resistência de planta adulta, uma vez que este tipo de resistência é do tipo não-específica à raça e geralmente é governada por genes com efeitos parciais e aditivos, e, embora a resposta à infecção seja essencialmente suscetível em fase de plântula, o desenvolvimento da doença élento (SMALE, 1998;JOHNSON, 1984). Alguns desses genótipos, como por exemplo, os representados pelos números $1,5,7,11,12,13,14$ e 15 tiveram níveis adequados de resistência não-específica, com reações suscetíveis, porém com baixa severidade consistentemente ao longo dos anos/locais. Níveis de resistência como os observados nesses genótipos podem limitar as perdas causadas pela ferrugem, e, além disso, este tipo de resistência tem demonstrado durabilidade por longos períodos de tempo (SMALE, 1998; JoHNSON, 1984). A durabilidade desta resistência é extremamente relevante nos países em desenvolvimento, onde muitos países não conseguem substituir cultivares no mesmo ritmo em que a resistência específica tem sido superada (TRETHOWAN et al., 2005).

Nas avaliações da reação em planta adulta (Tabela 4), verificou-se também que o comportamento dos genótipos representados pelos números 3, 15 e 20 foi semelhante à testemunha, cultivar IAC 370, especialmenteem CapãoBonito, ItapevaeParanapanema em 2004, quando foram registradas as mais severas epidemias de ferrugem da folha durante este estudo. Este fato demonstra que nos referidos ambientes havia alta pressão de inóculo virulento e em condições de ambiente favoráveis ao desenvolvimento da ferrugem da folha, e, portanto, corroboram a expressão de resistência de planta adulta nos genótipos citados.

A exigência de qualidade de trigo varia segundo a sua adequação a determinado uso final. Assim, a qualidade de qualquer tipo de trigo não pode ser expressa em termos de uma única propriedade, mas dependente de diversas, como moagem, processamento e características físicas da massa, cada uma delas com importância relativa na produção de pão, massas alimentícias, biscoitos, bolos ou produtos de confeitaria (Miranda et al., 2005).

A classificação da farinha dos genótipos de trigo de acordo com os seus diferentes usos na elaboração dos 
Tabela 4. Porcentagem de área foliar infectada em condições naturais no campo pelo agente causal da ferrugem da folha, (Puccinia triticina) nos genótipos de trigo avaliados em condição de sequeiro, nas localidades de Manduri (Zona A), Capão Bonito e Itapeva (Zona B) e em Paranapanema (Zona C), no Estado de São Paulo, no período de 2003 a 2005

\begin{tabular}{|c|c|c|c|c|c|c|c|c|c|c|c|c|c|}
\hline \multirow[t]{2}{*}{ Gen. } & \multicolumn{3}{|c|}{ Manduri } & \multicolumn{3}{|c|}{ Capão Bonito } & \multicolumn{3}{|c|}{ Itapeva } & \multicolumn{3}{|c|}{ Paranapanema } & \multirow[t]{2}{*}{ Reação } \\
\hline & 2003 & 2004 & 2005 & 2003 & 2004 & 2005 & 2003 & 2004 & 2005 & 2003 & 2004 & 2005 & \\
\hline 1 & $20 \mathrm{~S}$ & $5 \mathrm{~S}$ & $10 \mathrm{~S}$ & 0 & $10 \mathrm{~S}$ & 0 & $20 \mathrm{MS}$ & 0 & 0 & 0 & $10 \mathrm{~S}$ & 0 & $\mathrm{~S}$ \\
\hline 2 & $20 \mathrm{~S}$ & 0 & $20 \mathrm{~S}$ & 0 & $20 \mathrm{~S}$ & $10 \mathrm{~S}$ & $5 \mathrm{~S}$ & $20 \mathrm{~S}$ & $10 \mathrm{~S}$ & $20 \mathrm{~S}$ & 30MS & 0 & $\mathrm{~S}$ \\
\hline 3 & $20 \mathrm{~S}$ & $5 \mathrm{~S}$ & 0 & 0 & $30 \mathrm{~S}$ & 0 & $10 \mathrm{~S}$ & $20 \mathrm{~S}$ & 0 & $0-5 \mathrm{~S}$ & $40 \mathrm{~S}$ & 0 & $S$ \\
\hline 4 & $10 \mathrm{~S}$ & 0 & $10 \mathrm{~S}$ & 0 & $30 \mathrm{~S}$ & 0 & 0 & $20 \mathrm{~S}$ & $10 \mathrm{~S}$ & $10 \mathrm{~S}$ & $30 \mathrm{MR}$ & 0 & $\mathrm{~S}$ \\
\hline 5 & 0 & $\mathrm{tS}$ & 0 & 0 & 0 & 0 & $5 \mathrm{~S}$ & 0 & 0 & 0 & 0 & 0 & MS \\
\hline 6 & $10 \mathrm{MR}$ & tMR & $\mathrm{tS}$ & 0 & $30 \mathrm{MS}$ & 0 & 0 & $10 \mathrm{~S}$ & 0 & $10 \mathrm{MS}$ & $30 \mathrm{MS}$ & 0 & MS \\
\hline 7 & 0 & 0 & $5 \mathrm{~S}$ & 0 & $20 \mathrm{~S}$ & 0 & 0 & $10 \mathrm{MS}$ & $10 \mathrm{~S}$ & $5 \mathrm{MR}$ & $20 \mathrm{MR}$ & 0 & MS \\
\hline 8 & $10 \mathrm{MR}$ & tMR & 0 & 0 & $10 \mathrm{~S}$ & 0 & 0 & 0 & 0 & 0 & $10 \mathrm{MR}$ & 0 & MR \\
\hline 9 & $10 \mathrm{MR}$ & 0 & 0 & 0 & $\mathrm{tR}$ & 0 & $10 \mathrm{~S}$ & 0 & 0 & $0-\mathrm{tR}$ & $10 \mathrm{MR}$ & 0 & MR \\
\hline 10 & $20 \mathrm{~S}$ & $20 \mathrm{~S}$ & $20 \mathrm{MR}$ & 0 & $40 \mathrm{~S}$ & $20 \mathrm{~S}$ & 0 & $40 \mathrm{~S}$ & $10 \mathrm{~S}$ & $30 \mathrm{~S}$ & $30 \mathrm{~S}$ & $\mathrm{tS}$ & $\mathrm{S}$ \\
\hline 11 & 0 & 0 & 0 & 0 & 0 & 0 & 0 & $20 \mathrm{~S}$ & 0 & $10 \mathrm{MS}$ & $10 \mathrm{MS}$ & 0 & MS \\
\hline 12 & 0 & $5 \mathrm{~S}$ & 0 & 0 & 0 & 0 & 0 & $5 \mathrm{MS}$ & 0 & $10 \mathrm{MS}$ & 0 & 0 & MS \\
\hline 13 & 0 & $\mathrm{tS}$ & 0 & 0 & $10 \mathrm{~S}$ & 0 & 0 & 0 & 0 & 0 & 0 & 0 & MS \\
\hline 14 & $10 \mathrm{MS}$ & 0 & 0 & 0 & 0 & 0 & 0 & $5 \mathrm{MS}$ & $\mathrm{tS}$ & 0 & $20 \mathrm{MS}$ & 0 & MS \\
\hline 15 & $10 \mathrm{MR}$ & tMR & 0 & 0 & $40 \mathrm{~S}$ & $20 \mathrm{~S}$ & 0 & $40 \mathrm{~S}$ & $10 \mathrm{~S}$ & $20 \mathrm{~S}$ & $20 \mathrm{MS}$ & $\mathrm{tS}$ & $\mathrm{S}$ \\
\hline 16 & 0 & $\mathrm{tMR}$ & 0 & 0 & 0 & 0 & 0 & 0 & 0 & $\mathrm{tR}$ & $10 \mathrm{MR}$ & 0 & MR \\
\hline 17 & $10 \mathrm{MR}$ & $5 \mathrm{MR}$ & 0 & 0 & 0 & 0 & 0 & 0 & 0 & 0 & 0 & 0 & MR \\
\hline 18 & 0 & $5 \mathrm{R}$ & 0 & 0 & 0 & 0 & 0 & 0 & 0 & 0 & 0 & 0 & MR \\
\hline 19 & $10 \mathrm{MR}$ & $5 \mathrm{~S}$ & $10 \mathrm{~S}$ & 0 & $30 \mathrm{~S}$ & 0 & 0 & $5 \mathrm{MR}$ & 0 & $20 \mathrm{~S}$ & $20 \mathrm{MS}$ & 0 & $\mathrm{~S}$ \\
\hline 20 & $20 \mathrm{~S}$ & $\mathrm{tS}$ & 0 & 0 & $40 \mathrm{~S}$ & 0 & $20 \mathrm{MS}$ & $10 \mathrm{~S}$ & 0 & $20 \mathrm{~S}$ & $30 \mathrm{~S}$ & 0 & $\mathrm{~S}$ \\
\hline
\end{tabular}

$\mathrm{S}=$ Suscetível. $\mathrm{MS}=$ Moderadamente suscetível. $\mathrm{MR}=$ Moderadamente resistente.

Tabela 5. Peso Hectolitro (PH), extração experimental de farinha (Ext), número de queda (NQ) em segundos, e características farinográficas (absorção a 14\% - ABS, Tempo de desenvolvimento da massa - TDM e estabilidade - EST), alveográficas (P/L e W) glúten úmido (GU) e índice de glúten (IGU) dos genótipos de trigo avaliados em sequeiro, no Estado de São Paulo

\begin{tabular}{|c|c|c|c|c|c|c|c|c|c|c|}
\hline Gen. & $\mathrm{PH}$ & EXT & NQ & ABS & TDM & EST & $\mathrm{P} / \mathrm{L}$ & $\mathrm{W}$ & GU & GUI \\
\hline & $\mathrm{kg} \mathrm{hl}$ & $\%$ & seg & $\%$ & $\min$ & $\min$ & & $\mathrm{x} 10^{-4 \mathrm{~J}}$ & $\%$ & $\%$ \\
\hline 1 & 79.4 & 66.2 & 400 & 59,6 & 6.7 & 8.3 & 0.58 & 294 & 34.12 & 83,81 \\
\hline 2 & 77.9 & 66.5 & 400 & 66,8 & 5.8 & 7.1 & 0.72 & 403 & 44.47 & 93,45 \\
\hline 3 & 79.4 & 70.3 & 400 & 62,6 & 4.0 & 4.2 & 0.64 & 235 & 39.48 & 81,34 \\
\hline 4 & 80.3 & 69.3 & 399 & 63,1 & 7.0 & 10.6 & 0.79 & 407 & 41.74 & 93,93 \\
\hline 5 & 77.9 & 69.2 & 400 & 65,5 & 7.7 & 9.2 & 0.71 & 421 & 42.11 & 89,49 \\
\hline 6 & 75.9 & 68.6 & 389 & 66,0 & 4.0 & 6.8 & 0.65 & 246 & 50.87 & 74,41 \\
\hline 7 & 78.2 & 68.7 & 400 & 72,5 & 4.0 & 6.3 & 0.98 & 245 & 62.66 & 55,21 \\
\hline 8 & 79.0 & 71.2 & 388 & 65,3 & 5.5 & 6.7 & 1.02 & 316 & 39.23 & 75,70 \\
\hline 9 & 76.8 & 62.5 & 387 & 57,9 & 7.7 & 26.2 & 0.70 & 397 & 35.35 & 95,62 \\
\hline 10 & 79.9 & 70.9 & 419 & 60,5 & 6.7 & 11.5 & 1.15 & 335 & 31.82 & 95,38 \\
\hline 11 & 77.7 & 69.6 & 366 & 67,0 & 5.0 & 6.7 & 0.89 & 350 & 49.61 & 83,96 \\
\hline 12 & 79.0 & 69.7 & 367 & 59,8 & 3.7 & 4.4 & 0.60 & 232 & 44.88 & 72,70 \\
\hline 13 & 77.2 & 64.9 & 400 & 64,8 & 4.2 & 5.2 & 0.88 & 231 & 46.45 & 67,63 \\
\hline 14 & 79.9 & 75.5 & 400 & 64,7 & 6.0 & 6.0 & 0.71 & 295 & 41.26 & 87,53 \\
\hline 15 & 78.6 & 75.6 & 400 & 61,9 & 5.2 & 6.0 & 0.48 & 312 & 40.62 & 85,29 \\
\hline 16 & 74.7 & 64.6 & 358 & 59,6 & 4.9 & 6.5 & 0.44 & 209 & 43.44 & 78,43 \\
\hline 17 & 79.9 & 57.3 & 378 & 60,3 & 5.2 & 8.0 & 0.70 & 291 & 44.47 & 82,27 \\
\hline 18 & 77.0 & 73.4 & 372 & 65,2 & 4.3 & 7.2 & 0.71 & 305 & 45.09 & 77,71 \\
\hline 19 & 77.4 & 72.1 & 400 & 70,3 & 4.5 & 8.8 & 0.80 & 264 & 54.55 & 68,10 \\
\hline 20 & 79.0 & 71.6 & 384 & 68,4 & 5.3 & 9.1 & 1.27 & 286 & 49.27 & 80,75 \\
\hline
\end{tabular}

Fonte: Moinho Anaconda S/A. 
diversos tipos de farinha (Tabela 5) foram baseadas na Instrução Normativa n. ${ }^{\circ}$, de 15 de agosto de 2001, do Ministério da Agricultura, Pecuária e Abastecimento denominada "Regulamento Técnico de Identidade e Qualidade do Trigo", publicada no Diário Oficial da União de 21 de agosto de 2001, Seção 1.

Os genótipos 4, 5, 8, 9, 11, 15 e 18 e as cultivarespadrão IAC 24 e IAC 370 com características de trigo "Melhorador", força do glúten $\mathrm{W} \geq 300 \times 10^{-4} \mathrm{~J}$ (forte), os genótipos 4, 9 e a cultivar IAC 370 também mantiveram índices da estabilidade da massa superior a 10 minutos, dados considerados interessantes para a confecção de produtos que exigem farinha com melhores índices de tecnologia.

Um segundo grupo classificado como trigo "Pão", com energia de deformação da massa $W \geq 240$ x $10^{-4} \mathrm{~J}$ (médio) a $\mathrm{W} \leq 300 \times 10^{-4} \mathrm{~J}$ (forte) representados pelos genótipos $1,6,7,14,17,19$ e 20 e estabilidade da massa superior a 6,5 minutos seriam mais utilizados na fabricação de pães. No terceiro grupo, os genótipos cujas farinhas são consideradas indesejáveis, compostos pelos genótipos 3, 12, 13 e 16 tiveram a energia da deformação da massa $\mathrm{W}<240 \times 10^{-4} \mathrm{~J}$ e estabilidade abaixo de 6 minutos.

O objetivo da moagem é separar o mais completamente possível o endosperma da casca e do germe, e nesse contexto, o genótipo 9 foi o de menor índice de extração de farinha $(62,5 \%)$, consequentemente, o menor peso hectolitro $(76,8)$, característica de trigo semiduro. $\mathrm{O}$ índice de dureza expressa a dificuldade de desintegração do grão quando sobre ele é exercida pressão, portanto, os grãos mais moles representam menor porcentagem de farinha; em contrapartida no genótipo 9, constatou-se o melhor índice de glúten (GUI) $95,62 \%$, característica de farinha de boa qualidade.

\section{CONCLUSÕES}

1. O emprego da cultivar IAC 24 é bastante eficiente na obtenção de novos genótipos de trigo com bom potencial produtivo de grãos associados à boa qualidade tecnológica da farinha e resistência à ferrugem da folha no estádio de planta adulta.

2. O melhor rendimento de grãos é obtido pelo genótipo 7 (PF 87373/IAC 24), mas com o inconveniente de apresentar porte alto $(100 \mathrm{~cm})$.

3. Os genótipos 4, 5, 8, 9, 11, 15 e 18 destacam-se pela qualidade tecnológica de suas farinhas.

4. A cultivar IAC 24 e os genótipos descendentes 1 , $5,7,11,12,13,14$ e 15 que expressaram níveis adequados de resistência de planta adulta à ferrugem da folha podem ser utilizados em programas de melhoramento genético como fontes de resistência durável à essa doença.

\section{AGRADECIMENTOS}

Os autores agradecem aos técnicos de apoio Carlos Aparecido Fernandes, José Norberto da Silva e José Angelino de Paula pela colaboração no desenvolvimento dos experimentos, à ANACONDA - Indústria e Agrícola de Cereais S.A. pelas análises de qualidade industrial e à FAPESP, pelo apoio financeiro.

\section{REFERÊNCIAS}

AACC. AMERICAN ASSOCIATION OF CEREAL CHEMISTS. Approved methods of AACC. 9.ed. St. Paul, 1995.

ANIKSTER, Y.; BUSHNELL, W.R.; EILAM, T.; MANITERSKI, J. ROELFS, A.P. Puccinia recondita causing leaf rust on cultivated wheats, wil wheats, and rye. Canadian Journal Botany, v.75, p.2082-2096, 1997.

BRAMMER, S.R.;BARCELLOS, A.L.;MORAES-FERNANDES, M.I.B.; MILACH, S.C.K. Bases genéticas da resistência durável a ferrugem da folha do trigo e estratégia biotecnológicas para o melhoramento no Brasil. Fitopatologia Brasileira, v.25, p.520, 2000 .

BRASIL, Instruções Normativa N..$^{\circ}$, de 15/8/01. Ministério da Agricultura e Abastecimento. Diário Oficial da União, Seção 1, $21 / 8 / 2001$

CHAVES, M.S.; BARCELLOS, A.L. Especialização fisiológica de Puccinia triticina no Brasil em 2002. Fitopatologia Brasileira, v.31, p.57-62. 2006.

CHAVES, M.S.;BARCELLOS, A.L.; GERMÁN, S.;SCHEEREN, P.L.; DEL LUCA, L.J.A.; SILVA, M.S; CAIERÃO, E. Population dynamics of Puccinia triticina in the South Cone region of South America from 1997 to 2004. In: INTERNATIONAL WHEAT CONFERENCE, 7., 2005, Mar del Plata, AR. Abstracts... Mar del Plata: SAGPyA/INTA, 2005. p.130.

CHAVES, M.S.; WESP, C.L.; BARCELLOS A.L.; SCHEEREN, P.L.; SILVA, M.S.; CAIERÃO, E. Superação da resistência qualitativa da cultivar de trigo 'BRS 194' por uma nova raça de Puccinia triticina. Ciência Rural, v.39, p.228-231, 2009.

FELICIO, J.C.; CAMARGO, C.E.O.; GERMANI, R.; FREITAS, J.G.; FERREIRA FILHO, A.W.P. Rendimento de grãos e qualidade tecnológica de genótipos de trigo em três zonas tritícolas do Estado de São Paulo no biênio 1994-95. Bragantia, v.59, p.59-68, 2000.

FELICIO, J.C.; CAMARGO, C.E.O.; CASTRO, J.L.; GERMANI, Rendimento de grãos e sua relação com as doenças e variáveis climáticas em Capão Bonito de 1994 a 2001. Bragantia, v.63, p.93-103, 2004.

GERMÁN, S.; BARCELLOS, A.L.; CHAVES, M.S.; KOHLI, M.; CAMPOS, P.; VIEDMA, L. The situation of common wheat rusts in the Southern Cone of América and perspectives for control. Australian Journal of Agricultural Research, v.58, p.620-630, 2007. 
HUBNER, O. Análise da conjuntura agropecuária - safra 2007/2008. Trigo. SEAB, Secretaria da Agricultura e do Abastecimento do Estado do Paraná. 19p. 2008.

JOHNSON, R. A critical analysis of durable resistance. Annual Review of Phytopathology, v. 22, p. 309-330, 1984.

INSTITUTO AGRONÔMICO Recomendações Técnicas de Trigo para 2002. 3.ed.atual. Campinas, 2002. 92p.

LARGE, E.C. Growth stages in cereals. Illustration of the Feekes Scale. Plant Patholology, v.3, p.128-129, 1954.

LONG, D.L.; KOLMER, J.A. A North American system of nomenclature for Pucciniareconditaf.sp.tritici.Phytopathology, v.79, p.525-529. 1989.

MIRANDA, M.Z.; DE MORI, C.; LORINI, I. Qualidade do trigo brasileiro - safra 2004. Passo Fundo: Embrapa Trigo, 2005, 92 p.(Embrapa Trigo. Documento, 52)

PEÑA, R.J.; ORTIZ-MONASTEIRO, J.I.; SAYRE, K.D. Estrategias para mejorar (o mantener) la calidad panadeira en trigo de alto potencial de rendimento. In KOHLI, M. M. y D. MARINO (Eds.). Explorando Altos Rendimientos de Trigo. La Estanzuela, Uruguay, 1998. CIMMYT-INIA. p.289-306.

PIMENTEL-GOMES, F. Curso de estatística experimental 4.ed.ver.ampl. Piracicaba: Nobel, 1970. 430p.

RAIJ, B. van; CANTARELLA, H.; QUAGGIO, J.A.; FURLANI, A.M. Recomendações de Adubação e Calagem para o Estado de São Paulo. Campinas: Instituto Agronômico Fundação IAC, 1996. 285p. (Boletim técnico 100)
ROELFS, A.P.; SINGH, R.P.; SAARI, E.E. Rust Diseases of Wheat: Concepts and methods of disease management. México: CIMMYT, 1992. 81p.

ROSSI, R.M.; NEVES, M.F. Estratégia para o trigo no Brasil. São Paulo: Altas, 2004. 224p.

SCHRAMM, W.; FULCO, W.S.; SOARES, M.H.G.; ALMEIDA, A.M.P. Resistência de cultivares de trigo em experimentos ou cultivo no Rio Grande do Sul, às principais doenças fúngicas. Agronomia Sulriograndense, v.10, p.31-39, 1974.

SINGH, R.P. Association between gene Lr34 for leaf rust resistance and Leaf Tip Necrosis in wheat. Crop Science, v.32, p.874-878. 1992.

SINGH,R.P.;GERMÁN,S.;HUERTA-ESPINO,J.Genetic controlof wheat rusts in Latin America: current status and future challenge. In: CONGRESO LATINOAMERICANO DE FITOPATOLOGIA, 15., CONGRESO CHILENO DE FITOPATOLOGÍA, 18., 2009, Santiago, Chile. Resúmenes... Santiago: ALF, 2009. p. 39-42.

SMALE, M.; SINGH, R.P.; SAYRE, K.; PINGALI, S.; RAJARAM, S.; DUBIN, H.J. Estimating the economic impact of breeding nonspecific resistance to leaf rust in modern bread wheats. Plant Disease, v.82, p.1055-1061, 1998.

TILMAN, D., CASSMAN, K.G., MATSON, P.A., NAYLOR, R.; POLASKY, S. Agricultural sustainability and intensive production practices. Nature, v.418, p.671-677, 2002.

TRETHOWAN, R.M.; REYNOLDS, M.; SAYRE, K.; ORTIZMONASTERIO, I. Adapting wheat cultivars to resource conserving farming practices and human nutritional needs. Annals of Applied Biology, v.146, p.405-413, 2005. 
